\title{
Editorial:
}

\section{Retirement for the Rich and Retirement for the Poor: From Social Security to Social Welfare}

Fiscal pressures resulting from the national deficit and the current government's concern about jobs, has inadvertently cast the spotlight on older workers and their retirement. Widespread downsizing, significant layoffs, and a stubborn unemployment rate have reinforced public interest and, suddenly, gerontologists are being asked to make pronouncements on such matters as the best age for retirement or the de-indexing of pensions. With the unveiling of the latest Canadian budget and government promises of serious reform to social security in 1997, the questions have become more fervent. Should mandatory retirement be abolished? Will the Canada Pension Plan (CPP) really be bankrupt in 20 years? Will an aging workforce reduce Canada's productivity? Will the next generation honour the principle of intergenerational solidarity? Is universality dead?

On the one hand, this development can be viewed with some optimism. The issues of an aging workforce finally have become central to public debate, which is exactly where they belong as Canadians make decisions about who gets to work, who doesn't get to work, who pays, and under what circumstances. Gerontologists have an important contribution to make to the discussion in terms of informing and educating the public about the realities of population aging, and there is no better time than the present to make our voices heard. On the other hand, the newly found interest in the older worker and his or her retirement is somewhat suspect. The manipulation of factors that influence the labour force behaviour of older workers via pension and retirement polices has always been considered a legitimate means for managing the size and composition of the labour force and for thinning the ranks of corporations. It seems that now it is also a legitimate means for reducing the national deficit.

Poised on the threshold of sweeping changes to Canadian social policy, we are about to embark on yet another orchestration and rearrangement of the labour force, only this time, there is a sense of foreboding about the role older workers and retirement will play in this process of change. The emerging socio-political discourse is unenthusiastic about older workers and retirees: their supposedly better socio-economic status; their alarming numbers and the unreasonable strain they place on the public pension system are increasingly observed themes in discussions about Canada's social insurance programs.

Canadians have almost always had a compassionate view of the elderly and the latest population surveys still confirm this view. There is, however, a growing voice issuing from privileged Canadians, that older people should 
contribute more to reducing the deficit (Globe and Mail, 1995, p. A6). In a very recent study that surveyed Canadians on their attitudes toward government, their priorities and their spending, it was found that better-off Canadians are far more likely than others to think that their senior citizens should do more to contribute to fighting the deficit (Ekos Research Associates Inc., 1995). This perspective is fuelled by claims from government and business that poverty amongst the elderly has all but been eradicated and, since retirees have enough money, we can expect them to sacrifice in the name of the deficit. For example, the Canadian Institute of Actuaries when using the Sarlo poverty measure, states that "... poverty among the aged has been eliminated" (1995, p. 17). This message is a politer version of the "greedy geezer" argument, (Binstock, 1994), promulgated in the United States which makes it easier to politically market slashes to Old Age Security (OAS), the Guaranteed Income Supplement, or the Canada/Quebec Pension Plan (C/QPP). The apocalyptic demography arguments (Robertson, 1991) also still hold sway. There are too many older workers, taking too many jobs from too many unemployed younger persons. Older workers are clogging the higher echelons of company hierarchies and they are attentuating the career mobility of those who follow on their heels. These arguments represent a softer version of the "job snatcher" discourse found in France (Guillemard, 1983) and the notion that older workers must make way for younger workers. The demographic load (the ratio of pension beneficiaries to workers) is one of the apocalyptic scenarios that strongly points to changes in contributions to and reductions in the C/QPP and Old Age Security. Add the noticeable "graying" of the Canadian budget (over 20 billion dollars are transferred to seniors in pensions) to the equation, and it becomes almost routine to ask if we have the right to impose such a large economic obligation on future generations - the milder version of intergenerational conflict found in the United States. Superimpose on this scenario, the 1991 decision of the Supreme Court of Canada upholding mandatory retirement in those provinces with no human rights legislation protecting older workers, and we have a legitimate foundation for age discrimination in Canada. As Robert Binstock argues, the "... long-standing compassionate stereotypes of older persons have been undergoing a substantial reversal" (Binstock, 1994, p. 727).

Although there is a certain veracity to each of these concerns about older workers and their retirement, they are exaggerated and short-term issues and are frequently presented in very narrow economic terms (Binstock, 1994; Torres-Gil \& Puccinelli, 1994). For example, threats that the CPP will be bankrupt in the immediate future is not uncommon in the media (Globe and Mail, 1995, p. B1) and many commentators forget that the baby boomers will be replaced by the baby bust generation which will make fewer demands on the system. One could dispute every observation (see Binstock, 1944) but that is not the point of drawing attention to the changing stereotypes of older persons. These newer and less than compassionate stereotypes of the older worker/retiree help to weaken any responsibility society may feel towards this group and allows for changes in policy and programs 
that may be, at best, indifferent to most older persons and downright punitive to others. It is within this context that I consider the links between the labour force participation of older workers, pension policy and reducing the national debt.

In this issue, Ginette Lussier and Andrew Wister examine workforce aging within the British Columbia public service between 1983 and 1991. Their analysis reflects the trends occurring in most parts of the Western industrialized world - a middle-aging workforce, plateauing in the government bureaucracy, a stampede to early retirement stimulated by early retirement incentive plans, a reduction in the hiring of older workers and a high uptake of disability benefits, undoubtedly as an alternative route into early retirement. Their paper illustrates the powerful effect early retirement incentive programs have on slimming the labour force. What is of particular interest is, that once early retirement incentive plans were no longer offered after 1988, the rate of early retirement dropped substantially in the public service. The use of these programs in North America and Europe were initially put into place to avoid age discrimination and still get rid of older employees in order to ameliorate unemployment. Obviously, Canada is still on this course, although both the United States and Europe have abandoned these approaches because they are ultimately ineffective in reducing unemployment.

After promoting early retirement through the 1980 s, many western industrialized nations have come to the conclusion that the cost containment of pensions is the more pressing matter and have instituted a number of measures to reverse early retirement. The first line of defence has been to raise the retirement age as witnessed in the United States and Germany. A major justification for this move, is the resetting of the normal retirement age. Gains in life expectancy should be equitably distributed between working years and retirement years, thus the equivalent retirement age for 1995 would be 70 years of age (Chen, 1994). The reduction in morbidity rates amongst the aging population in the United States is used as an argument to rule out the specter of an aging work force riddled with poor health.

In this journal, a study of 11 male, senior administrators in the Quebec civil service by Daniel Tremblay suggests that an older age of retirement may bode well, at least for decision making, in the workplace. The results of the investigation suggest that aging is perceived by senior administrators as having a significantly favourable impact on their decision-making behaviour and that the impact has to do more with experience than with the fact that they are chronologically older. Although a positive finding, Tremblay notes that we know little about the actual benefits of experience.

Flexible retirement systems, or the redistribution of work time, is a related scheme that has also been proposed to reduce both the costs of pensions and unemployment. These programs have had limited success in Germany and France and, if the study by Lussier and Wister is any indication, Canadians aren't especially interested in these work arrangements. Only .01 per cent of B.C. government employees were engaged in job-shar- 
ing and only 5.5 per cent of employees worked part-time. Only 1 per cent of eligible management employees used a deferred salary leave program. One of the obstacles to the use of phased-in retirement plans is the possible reduction in benefits from public and private pensions in retirement, although it is not known if this was the case in the British Columbia public service. For phased-in retirement schemes to be effective in reducing labour force participation, the double penalty of losing current income and future income from pensions will have to be addressed. Raising current contribution patterns to account for the drop in future pension benefits may not be effective in light of the findings of Lussier and Wister. Almost no managers wanted to bank part of their salary for paid leave at a later date.

Another major response to the runaway costs of public pensions has been the shifting of expenses from the government sector to the semiprivate and private sector, a process already happening in Canada and in most other industrialized nations. Although there is a wide variety of proposed mechanisms for changing the structure of OAS and C/QPP to save money, the trend has been to enhance registered pension plans (RPPs) and registered retired savings plans (RRSPs). The extreme version of this position calls for the gutting of OAS and C/QPP and the institution of a universal super-RRSP system for Canadians (Globe and Mail, 1995, p. D6). That the new federal budget made a half-hearted attempt to reduce contribution levels to RRSPs and did not touch the lifetime capital gains exemption for small businesses is affirmation of this continuing trend. Those persons who receive benefits from this privately administered but publicly subsidized arrangement will undoubtedly do well in their retirement - those workers in the core and state sectors of the economy and the subjects of the two articles in this journal. The older workers who can take advantage of the semiprivate retirement system may become the only group that can afford to retire early. Business comes out ahead too, because the payroll tax associated with C/QPP is abolished.

But what about those who rely on the public pension system: mainly women and those men who have been part of the secondary labour market or those who have worked in the periphery of the economy? The purported redeeming feature of the super semiprivate system and the only reason Canadians are likely to endorse it, is the corresponding proposed super-GIS, an increased, Guaranteed Income Supplement, a means-tested program for the poor elderly. This last scenario will bring Canada full circle. In 1927 the Old Age Pensions Act was passed to supplement, not replace, the incomes of older workers 70 years and older, to provide a subsistence income to destitute workers, which was to be means-tested. The super-GIS, as a contemporary version of welfare, is not much different than the approach to welfare in 1927 which was based on the Elizabethan Poor Laws. According to the laws, the recipient of public aid was to be less eligible for the economic condition of the poorest paid worker, which is to say, they were to receive less from welfare than the poorest paid worker earned in the market place. Ultimately, disadvantaged older workers may be forced to remain in the labour 
force longer to avoid a life of subsistence in their retirement. If mandatory retirement is sustained in the seven provinces that endorse it, even this work option will evaporate and disadvantaged older workers will be forced into poverty.

Taking all the retirement rhetoric into account, it is not exactly foreseeable what fate will be meted out to older workers as the deficit comes under attack and pension policy is reconfigured, but the signs are ominous for those who are not advantageously positioned in the labour market. We already know that there is a relatively high level of income inequality in later life in Canada that stems from a lifetime of inequalities. The proposed changes to work arrangements and pensions that dominate the discourse about deficit reduction will serve to widen these income differentials among Canadians. Almost all proposals strike at the heart of universality and attempt to replace social insurance with social welfare. In short, we are on the brink of entrenching a two-tiered retirement system: one for the rich and one for the poor. J.S. Woodworth and A.A. Heaps, the prime movers behind the adoption of an old age pension in 1927 and who envisioned the pension to be a minimal measure against poverty, would roll over in their graves!

\section{References}

Binstock, R.H. (1994). Changing Criteria in Old-Age Programs: The Introduction of Economic Status and Need for Services. The Gerontologist, 34(6), 726-730.

Canadian Institute of Actuaries. (1995). Troubled Tomorrows - The Report of The Canadian Institute of Actuaries Task Force on Retirement Savings. Ottawa: Canadian Institute of Actuaries.

Chen, Y.-P. (1994) "Equivalent retirement ages" and their implications for social security and medicare financing. The Gerontologist, 34(6), 731-735.

Ekos Research Associates Inc. (1995). Rethinking Government, 1994 (p. 24). Ottawa: Ekos Research Associates Inc.

Globe and Mail. (1995). Canada Pension Going Broke. Feb. 25, p. B1.

Globe and Mail. (1995). Canadians Want Strong Active Government. Feb. 25, p. A6. Globe and Mail. (1995). Toward a Renewed Pension System. March 11, p. D6.

Guillemard, A. (1983). The making of old age policy in France: Points of debate, issues at stake, underlying social relations. In A. Guillemard (Ed.), Old Age and the Welfare State (pp. 75-99). Beverly Hills: Sage.

Robertson, A. (1991). The Politics of Alzheimers's Disease: A case study in apocalyptic demography. In M. Minkler \& C.L. Estes (Eds.), Critical Perspectives on Aging: The political and moral economy of growing old (pp. 135-155). Amityville, NY: Baywood Publishing.

Torres-Gil, F.M., \& Puccinelli, M.A. (1994) Mainstreaming Gerontology in the Policy Area, The Gerontologist, 34(6), 749-752. 